\title{
A Comparison of Paul K. Feyerabend's and Thomas Kuhn's Notions of Scientific Progress: Implications for African Philosophical Eclecticism
}

\author{
Ihejirika, Cardinal .I.C., Ph.D
}

Department of Philosophy, University of Port Harcourt, Nigeria

\begin{abstract}
Western civilization prides itself in having offered humanity a canon of institutionalized rationality namely, science. Consequently, scientists attribute to their discipline a bogus epistemological success. Regrettably, their failure to adopt a consistent method for doing science, questions the credibility of their superiority claims. Ceding ultimate epistemic authority to science therefore becomes increasingly difficult for disciplines like the humanities. This multiplicity of scientific methods manifest in different conceptions of scientific progress, which the post modernists perceive as methodologies. Against this backdrop, this essay undertakes a comparative examination of the notions of scientific progress in Paul K. Feyerabend and Thomas S. Kuhn. However, the aim is to identify the implications of such multifarious methodologies on the knowing process, and scientific progress generally and, also to show how African philosophical eclecticism represents a richer paradigmatic approach to knowledge acquisition. This particularly brings in the desired mark of novelty in this paper. The author adopts comparative analysis to arrive at its conclusion.
\end{abstract}

Keywords-Eclecticism, Methodology, Notion, Rationality, Science.

\section{INTRODUCTION}

Science has left no one in doubt as to its progressive character ever since it began to evolve into its modern form from the $16^{\text {th }}$ century till date. However this progress has been made possible by the scientific procedures as couched in what is popularly held as scientific method. It is by reason of this supposed consistency in method, that the scientific community prides itself as the very paradigm of institutionalized rationality. However, the truism or falsity of the forgoing claim can only be established or debunked after a proper investigation into the phenomenon of scientific progress or change. Both terms namely, progress and change are often helplessly intertwined. This is because change itself is inseparable with progress because there is never a progress without a certain measure of change. It may therefore not be out of place for us to shed more light on the concept of progress.

Definitively put, Uduigwomen (1992) conceives "progress as a forward movement, advance or development" (p.149). When it is applied to science, scientific progress would then literally denote, a discussion on the forward

ISSN: 2456-7620 movement, advance and development recorded in the scientific enterprise. Regarding this, Chalmers (1982) observes that "growth of science is continuous, ever onward and upward as the foundations of observational data is increased" (p.2). Besides, Newton-Smith (1981) adds that "the history of science is a tale of multifarious shifting of allegiance from theory to theory" (p.3). Accounting for these theoretical differences, is the divergences in the opinions of various scientists and philosophers of science regarding how best scientific progress should be pursued and here lies the spring board of the problem this research attempts to resolve. The discovery of this progressive route for science is a matter of necessity as a failure in this direction, will tantamount to sticking to a degenerative or unproductive ideas, in other words, the failure of science.

Against this backdrop, our study undertakes a comparison of Paul K. Feyerabend's and Thomas Kuhn's notions of scientific process. The aim is to identify their common weaknesses, which impede scientific progress and the epistemic implications these shortcomings hold for the knowing process, thus necessitating the researcher's 
proposal for the adoption of African philosophical eclecticism as a vent out of this epistemic challenge. For the purpose of clarity therefore, our research rolls off the ground with an exposition of the ambiguities involved in defining scientific method. This will be followed by the highlights of Feyerabend's and Kuhn's philosophies of science. The author will then draw the implications of both men's notions of scientific progress within which the need for Africa philosophical eclecticism will be created as a pathway to enhancing progress in human knowing process.

\section{AMBIGUITIES IN DEFINING THE SCIENTIFIC METHOD}

What is meant by scientific method is often erroneously and primarily taken to be the method adopted by scientists in their discoveries and experimentation. When this is parochially assumed to be the meaning of scientific method, many problematic issues arise. Rather, what is supposedly referred to as the scientific method is a cache of methodologies. This is what Cohel and Nagel(1978) perceive as: "a pursuit of truth as determined by logical considerations...this pursuit of truth is that attitude of the mind, which is characterized by rigor, rationality, objectivity, coherence and incisiveness" (p.192). Kanu, (2015) 'informs us that the scientific parlance namely, "scientific method" simply means "the process of deduction and induction" (p.79). While, Uduigwomen (1996), adds that: "while induction is the hallmark of science, deductive reasoning is regarded as the hallmark of logic" (p.72).Besides, Kazlev cited by Ihejirika (2015) identifies one of the most crucial undoing of the scientific method namely that, "scientific materialism accepts only one reality- the physical universe composed as it is of matter and energy, everything that is not physical, measurable or deducible from scientific observations is considered unreal... the poverty of this method lies in the fact that it is limited in telling us 'how' a process works not 'why' it works" (p.81).

Bales in his Evolution and scientific method (1976) notes this deficiency and declares that "the scientific method is incapable of dealing with the realm of purpose... it can only deal with cause and effect relationship, but cannot deal with the 'why', when one uses the term 'why' with reference to purpose" (p.37). Uduigwomen(2006) corroborates the above and avers that "by seeing the universe from this purely empirical method, science fails to understand that there are many other areas that they have not seen, for example, the metaphysical"'(p.57). Beside this, the scientific method is also incapable of making value judgment. Instead, it advances probabilities as its best answers and according to Edmondson (2006), "it turns its practitioners into lab rat" (p.164).For the purpose of this paper, our definition of scientific method philosophically leans on Kanu's conception of the term as the process of deduction and induction.

\section{HIGHLIGHTS OF PAUL K. FEYERABEND'S PHILOSOPHY OF SCIENCE}

To highlight the scientific philosophies of Feyerabend, expression must be given to his direct views on the seven headings that couch the said scientific philosophies. On each of these compacted and quoted seven headings, these views will be adumbrated for the sake of clarity. These seven headings are namely his views on: Against method; Counter protective method; Proliferation of theories; The failure of the general strategy; counter induction; incommensurability and finally his view on the ideology of science.

Before we dig deeper into these subheadings, it is needful to point out that Feyerabend aims at convincing his readership,that science is just but one tradition among many. Pertinent too, is the explanation that many scientific methods as used in this context embrace both the attempt at discovering rules and techniques to be employed in the discovery of theories. Beside this, is the study to uncover objective and justifiable principles for the evaluation of rival theories in the light of available evidences. The former is always suspect, whereas the latter, is welcomed as a legitimate endeavor by most philosophers.

Now, to Feyerabend view in 'Against method'.In this work, Feyerabend denies the existence of any legitimate distinction between discovery and justification. He proceeds to deny the existence of any method in science. Furthermore, he stands against the venerable tradition of scarcity for a system of rules, which is held as capable of guiding scientists in the business of theory choice. According to Feyerabend (1975), "no such system of rules can be found, and to adopt any particular rules or methodology can only have the effect of impeding scientific progress. The only principle that does not inhibit progress is anything goes" (p. 23).

On 'Counter Productive Method', Feyerabend tries to remind us that there is an interaction between reason and research.He posits a logical gap between the evidence of a theory and its truth or approximate truth, which is bridged by an inductive inference. According to his Against Method (1975): "The idea of a method that contains firm, unchanging and absolutely binding principles for conducting the business of science, meets considerable difficulty when confronted with the result of historical 
research. We find then, that there is not a single rule, however plausible, and however firmly grounded in epistemology, that is not violated at some time or other. It becomes evident that such violations are not accidental events; they are not results of insufficient knowledge or of inattention which might have been avoided" (p. 23).

Feyerabend hopes by this assumption to undermine the faith rooted in all rules of evidence by showing that any such rule has an equally counter-rule, the use of which would give opposite results. He however, failed to reckon with the fact that what one wants to preserve when faced with a choice between new rival theories is not the old theory itself but the observational successes of that theory. Besides, in 'Proliferation of theories', Feyerabend's motive here is to weaken all allegiance to the consistency conditionby developing a case for an incompatible counterrule, which in this case, enjoins to proliferate theories, especially theories that are incompatible with currently accepted ones. Feyerabend therefore, is of the view that we should proliferate theories that are at odds with accepted theories in order to improve our chances of discovering facts relevant to assessing the acceptability of the original theories since variety of opinion is necessary for objective knowledge. He opines in his Against Method (1975), that: "Theories should not be changed unless there are pressing reasons for doing so; the only pressing reason for changing a theory is disagreement with fact. Discussion of incompatible fact will therefore lead to progress. Discussion of incompatible hypothesis will not. Hence, it is sound procedure to increase the number of relevant facts. It is not sound procedure to increase the number of factually adequate, but incompatible alternatives" (p. 38).

Notably enough, Feyerabend remarks that he has not shown that proliferation should be encouraged rather, that the rationalists cannot exclude it. In the final analysis, it is incontrovertibly discovered that in the long run, scientific progress requires that the scientific community contains some heretics, who receive some support. Nevertheless, science would not flourish if everyone was all the time, trying to develop his own totally unique theory.

In the 'Failure of The General Theory', Feyerabend is criticized for regarding putative counter-productive instances as a principal of comparison. This singular act indicates that he erroneously assumes that the rationalist is committed to believing in exceptionless algorithmic principles of comparison. He also believed that one could equally abstract the system of rules from a consideration of magic, myth or early science. This view of his, has however attracted much criticism.
In 'Counter Induction', he rejects the idea that experience provides unproblematic evidence for the assessment of theories. For him, the development of theories incompatible with our considered judgment about the observational facts, will assist us in helping to improve those judgments. He held that our naïve views that theories ought to fit with the outcome of observation is a barnacle on the ship of progress. To do away with this obstacle, we need to press the second counter-rule.Furthermore, Feyerabend's views on 'Incommensurability', is summed up in his insistence on the untranslatability between incommensurable frame works. The impression given is that the meaning of all terms is dependent on their connection with the universal principles, such that if one alters a universal principal, all meanings change. If the principles are preserved, meanings cannot be constant across theory change. It is well nigh impossible to evaluate this picture.

Nonetheless, Feyerabend in 'Ideology of science' sees science as one ideology among a whole lot of others. The only constraint on an ideology is coherence.According to Newton-Smith (1981), "there is only one task, we can legitimately demand of a theory, and it is that it should give us a correct account of the world, i.e. of the totality of facts constituted by its own basic concepts" (p.131).Finally, Feyerabend believes that the priority, we attach to science arises from our belief in its method. "If science has found a method that turns ideological contaminated ideas into true and useful theories, then it is indeed not mere ideological, but an objective measure of all ideologies"(Newton Smith, p. 144). It is then not subjected to the demand for a separation between state and ideology. But the fairytale, is false hence, Feyerabend concludes that,there is no special method that generates successor makes it probable. All the same, Feyerabend concedes that science has made marvelous contributions to our understanding of the world and that this understanding, has led to even more marvelous achievements. He also adds that science today prevails, not because of its comparative merits but because the show has been rigged in its'favor(Science in a Free Society, 1978). This author will now proceed to consider the highlights of Thomas Kuhn's philosophy of science.

\section{HIGHLIGHTS OF THOMAS KUHN'S PHILOSOPHY OF SCIENCE}

Kuhn pictures science, as the very paradigm of institutionalized rationality. This is because, the scientist disinterestedly applies his special tool, the scientific method, and each application takes him further on the road 
to truth. Kuhn does not really look forward to his own conclusion that, there falls a shadow between the ideology of science and the realities of scientific practice. Rather, he suggests that mere reflection on the source of our scientific image is likely to prompt the conjecture that the image is gravely distorted. Thomas Kuhn in his own philosophy of science, emphasizes the notion of paradigm with which he wishes to eliminate such things as shared symbolic generalizations (which are basically theoretical assumptions held in common that are also deployed without questions), models (which are agreements either that particular analogies are treated as identities). Kuhn in his The Essential Tension gives us a very partial list of what he considered the features of a good scientific theory. He felt these will command majoritarian recognition of the proponents of other paradigms. According to him, a theory should among others be accurate within its domain, a theory should be consistent. It should also have broad scope. A good theory should be simple and also fruitful towards new research findings. It should be capable of disclosing new phenomena or previously unnoted relationship among those already known (1977, pp. 321322). For Kuhn in The Structure of Revolutions, the foregoing factors, suffice for persuading scientists to change their minds about theories (1970, p. 152). As values, theories, according to Kuhn, should be accurate metaphysical principles. They should be agreements on a particular assumption, which also plays a determining role in research, examples or concrete problems situations and capable of showing what constitutes problems in the field and on what constitutes their solutions. This embodies the genesis of Kuhn's notion of a paradigm, which he prefers to call a disciplinary matrix. Notably, Kuhn introduced the particular term, paradigm in the context of considering the application of predicates. Similarly, he employs the notion of an exemplar in giving his account of the meaning of scientific terms.The process of matching exemplars to expressions is initially a way of learning to interpret the expressions.

Additionally, Kuhn conceives normal science as puzzle solving, in the sense that during such a period, the energies of the members of scientific community are given to solving puzzles defined by the paradigm. And that leads to anomaly and the emergence of scientific discoveries.That apart, the changes effected by these discoveries are all distinctively as well as constructively undertaken. Nevertheless, there is always crisis in the emergence of any scientific theory and the significance of this crisis is the indication they provide that an occasion for retelling has arrived.
The response to this crisis is always the resulting transition to a new paradigm, which is scientific revolution. Confronted with anomaly or with crisis, scientists take a different attitude towards existing paradigms and the nature of their research changes accordingly. The proliferation of competing perspectives, the willingness to try anything; the expressions of explicit discontent; the recourse to philosophy and to the debate over fundamentals; all these, are symptoms of a transition from normal to extra ordinary research. At this point, the researcher will now undertake the actual comparison of the scientific philosophies of Feyerabend and Kuhn.

\section{PAUL FEYERABEND'S AND THOMAS KUHN'S NOTIONS OF SCIENTIFIC PROGRESS COMPARED}

The initial impression that comes to mind at the mention of the names of Feyerabend and Kuhn, is that both men are philosophers of science.This implies that both of them share a commonality in the adoption of critical approaches to scientific postulations and findings. Nevertheless, in this comparative analysis, it will be discovered that despite the commonalities both philosophers share, they also assume different stances on other issues. However, it is pertinent to note that both Kuhn and Feyerabend were probably nonrationalists though at their different levels.Hence, they shared the common opinion that theories are incommensurable. Whereas Kuhn specifically, prefers to represent his favorite example of incommensurability by an encounter between a proponent of Newtonian mechanics, and that of relativistic mechanics, Feyerabend thought differently. More often than not, it is discovered that both philosophers' views are given expressions in the English language, but when it comes to the real meaning of similar English words used by both, we observe that they use those similar words to denote dissimilar things in their respective polemics. Kuhn believes that there has been a shift in meaning, so extreme that concepts of a particular theory, cannot be adequately expressed in terms of the concepts of the other theory. The theories simply put, cannot be compared.If this was to be the case then, one would have to say incompatible things about mass, space, time, and so on. They werein fact; merely equivocating hence, their assertions simply pass one another without conflicting.

Feyerabend on the other hand, seems very much restrained than the early Kuhn, in his view of the extent of actual incommensurability. For him, it is only in certain conditions (only vaguely specified) that 
incommensurability arises. Feyerabend's own interpretation of those conditions has it that the particular theory change namely, from Newtonian mechanics to relativistic mechanics, glaringly counts as a case of incommensurability. Both Feyerabend and Kuhn pass from the thesis of incommensurability to a thesis of the relativism of truth. Due to the latter's (Feyerabend's) denial of any rules, having any real content or force that can be abstracted from scientific practice, he has been found to be more radical in his critique of rationalism than Kuhn, but Kuhn still hold that there are rules held in common by all members of the scientific community.

In any case, neither Kuhn nor Feyerabend accepts the indeterminacy of radical translation. All the same, Kuhn failed to offer any solution of the discovery of any sense in which theories of truth and inference are in competition. Rather, he inconsistently explicates the notion of competition in terms of the notion of logical incompatibility, while Feyerabend, talks of theories as being rivals, without explaining in what the rivalry consists. Both philosophers therefore suffered the common weakness of not exactly providing us with the answer to the question, they both discovered.

Feyerabend and Kuhn jointly attacked the conception of a dichotomy between theory and observation. The rallying cry became that all observation is theory-laden. What this means is that, there is no such thing as a theory neutral observational language. Again, neither Kuhn nor Feyerabend, accept the indeterminacy of translation. Kuhn rather, emphasizes the conceptual meaning of terms, but in all, both men assumed that while we cannot express one theory in terms of language of the other, that we can, never the less, come to have some understanding of both theories. Hence, while divergences held sway in certain scientific philosophies of both men, agreement flourished in the rest.

\section{AFRICAN PHILOSOPHICAL ECLECTICISM AS A POSSIBLE BYE-BLOW OF FEYERABEND'S AND KUHN'S NOTIONS OF SCIENTIFIC PROGRESS}

The philosophical tradition of eclecticism, has its roots among a group of Ancient Roman Philosophers, who had no particular attachment to no real system, but selected from existing philosophical beliefs, which ever doctrine that tickled their fancy as reasonable. The word, eclecticism being of Greek origin-eklektikos, literarily means 'choosing the best'. Among the Greeks, notable eclecticists included: The Stoic-Panaetius (150B.C.E), Posidonius (75 B.C.E), The New Academic Carneades (155 B.C.E), and Philo of Larissa(75B.C.E). The exponents of this school of thoughtamong the Romans according to Zela Eduard (2001) were namely, Cicero, (who invented the peripatetic's, Stoics, and the New Academic Doctrines);Antiochus of Ascalon, (who influenced the transition of the academy from skepticism to eclecticism), and persons like Varro and Senecca, the Younger (p. 255).

However, eclecticism does not necessarily stick rigidly to any singular paradigm; rather, it employs multiple theories or ideas in order to achieve complementarity and comprehensive insights into their subjects. It, therefore, operates without conventions or rules that dictate how theories are combined. Consequently, it has severally been criticized for paucity of consistency and lack of simplicity. Schneider has Johann Jakob Bucker as the person to have methodically structured the history of Philosophy. Bucker's new ordering of the history of philosophy distinguishes three main periods. He details the presentation of the philosophies and groups of philosophers in his Ideas of An Eclectic Philosophy. Schneider (2016) quotes Bucker as positing that, “...preferring eclecticism is for Bucker, not riding with any philosophical orientation, because that will transform his own judgement into a commentary. It is, rather, a concept ruling the overall historical view, the articulation and the critical analysis of his history of philosophy" (p. 1).

In Bucker's theorizing, Philosophic Eclectica has three meanings. First, it represents a historical phenomenon, which he calls the Philosophy of Alexandria, in which clerical and Christian ideas come together. He tags this, a false eclecticism or syncretism. Secondly, Bucker conceives philosophic eclectica as the main thread of modern philosophizing since the Renaissance.It is also a fact of the most recent past in his own time, which he includes in his history of philosophy. Thirdly, Bucker who indicates that, fundamentallyall philosophers are eclectics in so far as they started something new and could make use of the predecessors in limited ways opposing or supporting these previous views in the process of their philosophizing. Thinning our meaning of eclecticism down to its African perspective, which represents how this term is to be understood in the context of our present work, African philosophical eclecticism is to be seen as a school of thought in African Philosophy conceived as the best approach to doing African philosophy. Uduigwomen(1995) explains that, "This school holds that an intellectual romance between the Universalist conception(of African philosophy, which projects the tenet that philosophy is the same everywhere-additions mine) and the Particularist conception(which holds that for philosophy to be worth its salt, it must have local 
relevance-additions mine) will give rise to an authentic African philosophy... the universalist approach will provide the necessary analytic and conceptual frame work for the Particularist approach. Since this frame work cannot thrive in a vacuum, the Particularist approach will supply the raw materials or data needed by the Universlist School. Thus, it will deliver the Universalist approach from mere logic-chopping and abstractness. There will be a fruitful exchange of categories and concept" (p. 6).

By the latest Uduigwomen's submission, African philosophical eclecticism provides the best framework by which African philosophy can employ relevant Western categories and concepts. Similarly, the most scientific Western philosophy can as well, borrow some relevant African categories and concepts. This looks like a proposal of a marriage of convenience whereby a humble interchange of ideas between Western and African philosophies, will symbiotically and complementarily enrich each other. The advantages of such a symbiotic union among others include the facts that this eclectic method saves both philosophies, the intellectual arrogance called epistemic naivety- an attitude, which makes one philosophy to treat others with derision consequent upon mere cultural differences.

Besides, such eclectic approach brings local relevance to Western philosophies hitherto considered alien and abstracted from African reality. For instance, and as Uduigwomen(1995) remarks, "The mind-body problem will not make much sense to the traditional African except it is discussed within the context of African's cultural or existential situation. Such a discussion, must include African construal of the nature of the body and soul, after life etc." (p.7). The citation above indicates that it is both a truism, that there can be a universal scientific philosophy as well as a true traditional, cultural, even artistic or humanistic personal philosophy. If our foregoing views are anything to rely upon, an ethno-philosopher, who undertakes a critical reflection upon African world views, is indeed justifiably, a philosopher. The individual thinker too, whose ingenuity grants the production of an original reflection of philosophical problems of his society and milieu, does also a recognized version of philosophy. What is being proposed here is neither the carving out of a portion of reality and labeling it African nor the synonymous equation of African culture with philosophy (as all lands have their cultures). Rather, our point is that philosophy can be adapted to explain reality in African or western perspectives. As Sodipo(1983) puts it, "When you say 'African philosophy', you are drawing attention to that aspect of philosophy which arises from the special problem and the unique experience of African people" (p. 6).
The challenge now is, how do we relate the foregoing African eclectic proposal, (the application of which we have already highlighted its merits) to Feyerabend's and kuhn's notion of scientific progress considering the observation by Anthony Giddens in his Profiles and Critiques in Social Theory that, the "orthodox model of natural science is now itself no more"(1982, p.201).It must be noted that Feyerabend and Kuhn disagree at some points in their use of language and argument surrounding incommensurability of theories and scientific paradigm shifts.This lack of an agreed method seems to retrogressively serve the interest of science. The impression created seems to favor the adoption of a polymethodical approach such as is advanced by African philosophical eclecticism. The latter, seems more attractive given the limitations of a singularity of opinion and method, which leaves an imprint of epistemic loneliness on all philosophical traditions, more so, when they neglect other perspectives. If the history of science as Newtonsmith(1981), would have us believe, consists of "a tale of multifarious shifting of allegiance from theory to theory"(p.3), what harm shall we inflict on science, when we identify with Kuhn that during normal science, scientist direct their energies to solving puzzles defined by their paradigm, which according to him creates anomaly? At the same time, what harm also shall we do to science, if we alsoaccept Feyerabend's consideration of the result of historical research, and by the function of the embrace of both Kuhn's and Feyerabend's ideas above, posit that scientific progress is better enhanced when we allow methodologies to thrive in the spirit of eclecticism instead of a singular method? Granted that philosophy is philosophy everywhere (whatever that may entail), we are still confronted daily with the challenge of convincing the world about the relevance of this discipline and until philosophy fills such lacuna created by science, she may be far from serving a historical purpose. Here, then, is where the eclectic method comes in to complementarily make up for what is lacking in both Feyerabend's and Kuhn's notions of scientific progress.

The adoption of an eclectic method among Africans, having been informed by our comparative study of Feyerabend's and Kuhn's notions of scientific progress, certainly shows that the detachment of philosophy from the very issues that are supposed to be of philosophical relevance, will end up making philosophy a rarefied discipline just as the comparative analysis above indicates. Similarly, employing a singular method in doing science,will thin down its wealth and impede scientific progress. If a singular scientific method could go with the 'almighty tag', there would not have been multi- 
disciplinary and inter-disciplinary interactions in academics. In as much as the intellectual elite of any milieuconstitutes a 'think-tank' group, on which their society's progress hinge, there is also, an additional need for this group, not to be confined in the circumference of only the Ivory Towers or to a singular method, which impoverishes research. When we make appeal to the eclectic approach (to knowing) in philosophy, man's progress is enhanced by the understanding of his natural environment. The examples of Professors' Godfrey Ozumba's(2017)Trajectory of the Philosophy of Integrative Humanism; Innocent Asouzu's (2011) Complimentary Reflections on Ibuanyidanda and Dr. Cardinal Ihejirika's(2017) Akonucheism are latest cases in point in the direction of our proposal. As Feyerabend (1978) puts it, "Science being only one of the many instruments humans invented to come to terms with their surroundings is not the only one and may not be infallible rather, it has become too powerful, too pushy and too dangerous to be left on its own" (p.160).Uduigwomen(2007) supports the above approach and opines that, "To see life holistically, we need science plus ethics, religion, philosophy, art, and other disciplines...(;) a combination of all will not only help mankind to regain its lost sense of human values of morality and traditional culture caused by the deification of science, it will also go a long way in putting society on the path of balanced development"(p. 155).

Kalu (2015), in tandem with Uduigwomen, asserts that: "man cannot leave by science alone"(86). Scarce wonder then, Kurtz cited in Burr and Goldinger (1977) writes that: "these human longings(referring to Metaphysics, Religion, and the aesthetic parts of life-additions mine) can be satisfied by deliberate cultivation of the arts in such a way as to richly compliment rather, than destroy critical intelligence"(p. 435).

\section{CONCLUSION}

This study has established the fact that both Feyerabend and Kuhn undertook their philosophies of science in order to water down claims of the rationalists, so as to institute what they thought would be a better objective edifice to knowledge of realities instead of baseless claims emanating from both the rationalists and over-assuming scientific community. It could also be noted as Feyerebend (1975) did in his Against Method that the idea of a fixed method, or a fixed theory of rationality, rests on too naïve a view of man and his social surrounding; hence, this paper reckons with the reality that in science and of course, every development research endeavor, is propelled by challenges after which a less appreciative previous phenomena metamorphoses into a more appreciable heuristic. Hence, every crisis or academic polemics, carries within them, seeds of development when carefully guided, guarded and directed. When we do away with the raising of puzzling questions on certain scientific assumptions, erroneous theories may become perpetuated as standards. However, it takes the capabilities to adjust and insightful capacities of the human species, not only to identify theoretical weak points and loopholes in prevailing ideologies, but also, to suggest better vents out of such epistemic cul-de-sac. In the case of this present study, the researcher, have found out that a comparison of Paul K. Feyerabend's and Thomas Kuhn's notions of scientific progress, exposes intolerable epistemic naivety, hence, in order to overcome this visible lacunae, the present researcher, suggests philosophical eclecticism, which encourages multi-disciplinary interchange of ideas and the symbiosis of the merits of both the scientific cum cultural epistemologies in the quest for problem solving. The eclectic wealth consists in its complementarity, such that, the shortcoming of a particular ideology or theory is made up by another in a rhythm that enriches the human knowing process.

\section{REFERENCES}

[1] Asouzu, I. (2007). Ibuanyidanda: New Complementary Ontology Beyond World - Immanetism, Ethnocentric Reduction and Impositions. Zurich: Transaction Publishers.

[2] Bale, J.D. (1979). Evolution of Scientific Method .Scary: A.R. Bales

[3] Burr, J.R., Mitton G., (1977). Philosophy and Contemporary Issues. 5thedition. New York: Mc Graw Hill Books.

[4] Chalmers, A.F. (1982). What Is This Thing Called Science? $2^{\text {nd }}$ edition, Queensland: Queensland University Press.

[5] Cohen, M., Ernest N., (1978).An Introduction to Logic and Scientific Method. London: Routledge and Kegan Paul.

[6] Edmondson, H. (2006). John Dewey and the Decline of America's Education. Indianapolis: Indiana University press.

[7] Feyerabend, P. K. (1975). Against Method. London: New Left Books.

[8] Feyeraband, P. K. (1978). Science in a Free Society. London: National Library Publication.

[9] Giddens, A., Dallmayr, R.F. (1982). Profiles and critiques on social theory. California: Macmillan Educational Books.

[10] Ihejirika, C. I. (2015). Techno-Scienticism and National Development in Nigeria: A Philosophical Reflection. Uma: Journal of philosophy \& religious studies. 10.83-94.

[11] Ihejirika, C. I., Emedolu, C.I. (2017), Rethinking John Dewey's Instrumentalism vis-a-vis the Igbo notion of "Akonucheism". International Journal of Arts and Humanities4(6). 37-51. 
[12] Kanu, M. (2015). The limitations of science: A philosophical critique of scientific method. IOSR Journal of Humanities and Social Sciences (10SR-JHSS). 20(7), 80-91.

[13] Kuhn, T. S. (1970). The Structure of Scientific Revolution.2nd Edition. Chicago: University Press.

[14] Kuhn, T. S. (1977). The Essential Tension. Chicago: University Press.

[15] Newton-Smith, W.H. The Rationality of Science. Oxford: Routledge and Kegan Paul.

[16] Ozumba, G.O. (2017) Trajectory of the Philosophy of Integrative Humanism. New York, U.S.A: Lulu Publishers Illinois Press.

[17] Schneider, W.J. (2016). The Problem of Eclecticism in the History of Philosophy. Intellectual History Review26 (1), 117-129.

[18] Sodipo, J.I., (1983). An Interview in the Philosopher: An Annual Magazine of Nigeria Association of Philosophy Students. UNIFE Branch I (1).

[19] Uduigwomen, A.F. (1992). History and Philosophy of Science. Aba: A.A.U. Industries Publishing Division.

[20] Uduigwomen, A. F. (1995). (Ed). Footmarks on African Philosophy. Lagos: OOP. Press.

[21] Uduigwomen, A.F. (2007). A textbook of History and Philosophy of Science. Aba: Vitalis books.

[22] Watkins, W. N. (1970). Against Normal Science. Lakatos. Imre (Ed.) Criticism and the growth of knowledge. London: Cambridge University Press.

[23] Writh, J. S., (2016). In Problem of Eclecticism in the history of Philosophy. Intellectual History Review, 26(1), 117-129.

[24]Zeller, E.(2001).Outline of the liberty of Greek philosophy. $13^{\text {th }}$ edition. Oxon: Routledge and Kegan Paul. 